\title{
Cargo Cults in Information Systems Development: a Definition and an Analytical Framework
}

\author{
Tanja Elina Mäki-Runsas \\ CERIS, Department of Informatics, Örebro University \\ Örebro, Sweden \\ Kai Wistrand \\ CERIS, Department of Informatics, Örebro University \\ Örebro, Sweden \\ Fredrik Karlsson \\ CERIS, Department of Informatics, Örebro University \\ Örebro, Sweden
}

tanja.maki-runsas@oru.se

kai.wistrand@oru.se

\begin{abstract}
Organizations today adopt agile information systems development methods (ISDM), but many do not succeed with the adoption process and in achieving desired results. Systems developers sometimes fail in efficient use of ISDM, often due to a lack of understanding the fundamental intentions of the chosen method. In many cases organizations simply imitate the behavior of others without really understanding why. This conceptual paper defines this phenomenon as an ISDM cargo cult behavior and proposes an analytical framework to identify such situations. The concept of cargo cults originally comes from the field of social anthropology and has been used to explain irrational, ritualistic imitation of certain behavior. By defining and introducing the concept in the field of information systems development we provide a diagnostic tool to better understand one of the reasons why ISDM adoption sometimes fail.

Keywords: Agile development, Cargo cult, Method Rationale, Self-Determination theory, Social-action theory, Information systems development, Information systems development methods, Software development, Software development methods
\end{abstract}

\section{Introduction}

Inefficient information systems development (ISD) is a prevailing challenge in many organizations. For example, over the years the Standish Group CHAOS reports [50-52] have showed that ISD projects have had difficulties in meeting their targets. In response to this challenge organizations adopt various kinds of information systems development methods (ISDM). The adoption and use of ISDMs is not a new phenomenon, since ISDMs first appeared during the 1960s as a response to what was once coined the "software crisis" [9]. Early approaches tried to handle problems identified in ISD without any plans, often by developers who did not know the business context the suggested systems were planned to support [4]. Today, a vast number of different ISDMs has been proposed. Jayaratna estimated already in 1994 that approximately 1,000 named ISDMs existed [34]. This number has most likely increased even more today. A problem related to many of these ISDMs is that they became more and more administratively heavy, and more difficult to follow and understand [32].

As a backlash against this development, agile ISDMs were proposed which aimed at flexibility and faster delivery [5, 7, 12, 14]. These ideas were unified in 2001 when a group of experienced practitioners and researchers formulated what became known as the Agile Manifesto (www.agilemanifesto.org). The manifesto stated that four main values are important in order to succeed with agile ISD; (1) individuals and interactions over processes 
and tools, (2) working software over comprehensive documentation, (3) customer collaboration over contract negotiation, and (4) responding to change over following a plan. These main values resulted in twelve principles that systems developers should adhere to while working. The point of this manifesto was to increase ISD efficiency. All agile ISDMs should implement these fundamental ideas, which for example means involving customers early and continuously, and responding to change through continuous software deliveries. Another fundamental point is to always welcome changing requirements and having an open working environment where business people and developers work together with an effective and short timescale, having a constant pace. The individuals involved should be kept motivated throughout the whole process in order to promote team spirit [6].

Nowadays many ISD organizations have adopted various kinds of agile ISDMs [17, 24] and thus making them common. An inherent characteristic of agile ISDMs - being lightweight methods - is their apparent lack of clear guidelines and direct instructions of how to conduct ISD. An obvious benefit of agile ISDMs is that they are presented as easier to follow, more flexible and easier to adopt than more traditional ISDMs [24]. Thus, many ISD organizations, which have adopted some kind of named ISDM, claim to be agile. However, it is unclear to which degree they are actually being agile, i.e. following the underlying values and principles of the agile manifesto. That said, some ISD organizations that claim to be using agile ISDMs are very successful, such as Spotify and King. At the same time, an extensive number of ISD organizations seem to fail in their efforts to adopt an agile ISDM [2, 40]. Both results are natural, considering that systems developers use their situational and local character of knowledge when adopting an ISDM, resulting in differences in method-in-action [22]. Although our discussion above uses the more recent developments on ISDMs and agile ISDMs in particular as an example, this challenge applies to the adoption of more traditional types of ISDMs as well. All ISDMs are normative artifacts, which means they are based on values that have guided the method design. Thus, irrespective of the chosen method there is a need to be compliant with its values in order to be true to the method. Despite that this is known and that ISDMs have been on the research agenda for several decades, scholars have mostly focused on to what extent ISDMs are claimed to be used [cf. 42] and local adaption of methods [e.g. 3, 22, 37]. Less attention has been given to flawed or failed adoption and the reason behind these situations.

In order for practitioners and researchers to identify challenges related to ISDM adoption there is a need for useful analytical frameworks that direct attention. One way of pinpointing challenges in adopting ISDMs is to explore to what extent unsuccessful attempts are examples of "cargo cult" behavior. The concept of cargo cults originally comes from the field of social anthropology and is used to explain irrational imitation of rituals [20,56]. This concept has been used among consultants as a metaphor when describing how an ISD organization fails to adopt an agile ISDM because they act upon and follow method descriptions, or imitate others, without understanding the underlying values and reasons behind the method. This results in misconceptions and ritualistic behavior, which does not contribute to reaching the actual ISD goals. Examples of how cargo cult has been used as a metaphor in the industry can be found in blogs by James Shore, Maxx Daymon, Jose Luis Soria and others [15, 48, 49]. Originally, the concept was used to describe ritualistic, uncontested imitation by different cultures in the Melanesian islands. These futile attempts to replicate the western visitors' behavior were carried out with the purpose to be rewarded with gifts from the gods. These gifts, or "cargo", were regarded by these cults as something magical, which would appear when they performed certain rituals [56].

Against this backdrop, the aim of this conceptual paper is twofold: a) to define the concept of information systems development method cargo cult, and b) to suggest an analytical framework that could be used to identify information systems development method cargo cult situations in an ISD organization. To this end we employ the original definition of cargo cult by Worsley [56], Weber's [54] typology of social action as interpreted by Kalberg [36], and Self-Determination Theory [45]. The typology of social actions is used to distinguish between rational, irrational and non-rational social actions with regards to the goals and values of the chosen ISDM. Self-Determination Theory is used to describe the 
motivation behind social actions. Subsequently, this paper provides information system (IS) researchers with an alternative theoretical perspective and an analytical framework to identify flawed adoption of ISDMs. It provides managers and systems developers in ISD organizations with a diagnostic tool making it possible to identify cargo cult situations in organizations, which opens opportunities for future process improvements.

The paper is organized as follows. The next section presents an overview on research related to cargo cults and to what extent cargo cults have been addressed in IS and ISD. This is followed by a theoretical section on ISDM, which provides a background to understand the complexity of this type of artifact and why misconceptions and ritualistic method behavior can occur. The next section contains our conceptual development, resulting in our definition of ISDM cargo cult and the suggested analytical framework. Finally, we end this paper with a short conclusion and discussion of directions for future research.

\section{Research Related to Cargo Cults}

As discussed in the Introduction, the concept of cargo cults was identified among the natives in Melanesia and defined by Worsley [56] from a socio anthropological perspective. Many examples of cargo cults have been reported, typically describing the phenomenon in different cultures less technologically advanced in comparison to western society [16, 33, 55, 56]. These studies described the seemingly futile attempts to imitate western visitors in the hope that the gods will reward them with gifts. An example could be to construct an airfield in the dirt and an airplane out of palm leaves to lure the gods to the island. The natives of Melanesia did this because they did not understand why the airplanes came in the first place. Nor did they understand the purpose of an airfield and how a construction must be coordinated with other efforts in order to make sure airplanes will actually come.

The purpose of an airplane is to go from A to B. Usually in order to deliver something, persons or cargo. If you choose to build an airfield, you have to make sure that this airfield is known to others, typically people interested in directing airplanes from A:s to B:s. You must also understand the basic requirements for an airfield. This could be aspects concerning length and material of the runway to accommodate airplanes up to a specific size. You must also understand regulations regarding air traffic control systems, possibly radar, air routes, fuel, security, customs, logistics and so on. This requires coordination and communication with others and most importantly an understanding of how and why the airfield is supposed to operate with other actors. The natives of Melanesia simply replicated what they observed without understanding the underlying reasons and requirements for an airfield; they were exerting a cargo cult behavior. The problem was not really the location of the airfield itself. Many islands in Melanesia have since then gotten airfields of their own. However, these airfields have been designed with a different kind of understanding. Just building an airfield through imitation does not result in airplanes landing. Other things do.

Typically, a cargo cult is understood as a temporal situation, which means that it is possible to overcome this state. That said, there are examples of cargo cults that persist in some form over decades. One such cargo cult is the "John Frum" cult of Tanna [26], which still exists today. Moreover, it is important to acknowledge that cargo cults are not only found in cultures considered less technologically advanced in comparison with western society. One example of a cargo cult in a western society can be found in the case of the UFO-sect Heaven's Gate. In 1997, 39 members of this sect committed suicide in the hope that their souls would be picked up by a UFO accompanying the Hale-Bopp comet. They were found at their compound in San Diego, CA, dead by poisoning and each one covered by a purple cloth. The inspiration for this came from science fiction and their leader Marshall Applewhite convinced the members that this was the rational thing to do [25]. The behavior is in line with what is typical for a cargo cult.

The concept of cargo cult has been sparsely used in the IS field, but when it is used one can see it is disparately used with many different meanings. McConnell [40] tried, in an editorial, to introduce the concept by explaining this behavior in ISD organizations. He wrote about impostors and misuse of processes, however he did not present any research to validate 
his opinions. We can also see the metaphor being used to describe robot research [19] and interaction design prototypes [29]. Cerf [11] used the concept in information technology environment development and explained how industrial parks are created through imitation with the blind belief that they would generate the same success as others. These examples all describe a certain behavior, which involves imitating others without understanding why.

Imitating behavior implies trying to act like someone else. Uncontested imitation without regards to, or comprehension of, the underlying reasons could lead to meaningless rituals. Feynman [20] introduced the concept of cargo cult science as a metaphor for describing scientific research of low validity and referring to the uncontested imitation of research methods without regards to whether they were actually appropriate in a given research study. As methods are common in ISD, one can question if not the same situations might occur in different ISD organizations, leading to the following of meaningless rituals. Obviously, this might inhibit an ISD organization in reaching the desired success.

The notion of cargo cults in ISD can also be related to attempts to understand how ISD organizations deviate from standard ISDM application principles. For example, one way to describe such deviations in the agile context is to refer to them as ScrumButs. This indicates that an ISD organization is using Scrum, but still chooses to not implement Scrum in full, omitting possible important aspects. Such deviations have been described using the term Antipatterns as a way of describing agile malpractices $[10,18,28]$. So far, the research on Antipatterns have not been aimed at finding a theoretical framework that could explain the problems concerning agile malpractices, but rather to collect instances of malpractices, suggest remedies, and record them as different types of Anti-patterns.

\section{Information Systems Development Methods}

Earlier we concluded that ISDMs have been around for a long time. This means that scholars have invested a lot of effort into understanding and explaining what an ISDM is. Hence, there exist a number of definitions [1, 8, 30, 31, 38, 41, 44, 58]. However, Karlsson and Ågerfalk concluded [38] that although these definitions are slightly different, there seems to be a shared understanding that an ISDM has three main parts; concepts, activities and notations.

Let us take one of the practices of an agile ISDM, Daily Scrum, as an illustrative example. It contains a description of what is meant by this practice; it should be carried out as time-boxed daily meeting, to synchronize the ISD team's efforts and plan the work for the next 24-hours [47]. In other words, concepts relevant in a Daily Scrum are; time-boxed, daily meeting, synchronizing efforts and short-term planning. Concepts in this sense emphasize what is considered important in the ISDM. Concepts must be operationalized and have certain activities making sure that the ISD team focuses on the concepts in a fruitful way, typically by asking questions. If the Daily Scrum is meant for the ISD team to synchronize development issues, questions need to be asked during the meeting to create a shared understanding for everyone involved in the project. These questions should help the team members to understand the current state of the system, the progress of the ISD activities, and current tasks and challenges. Since this meeting is being carried out every day, shared understanding is therefore created on a daily basis. Typically, the results of ISDM activities are recorded in some way, constituting the method's notation. However, since no shared records are produced during a Daily Scrum, the notation is an individual choice of the team members - sometimes being nothing more than mental notes.

Another example could be the Product backlog. A product backlog consists of a list of things that need to be completed. The list is organized as prioritized and estimated work items that an ISD team picks in order to know what should be done during the next iteration [47]. Some of the concepts relevant for a Product backlog are; work item, priority, and estimation. Activities that relate to these concepts are, for example, to divide the work that needs to be done into specific work items, prioritize these work items, and thereafter to estimate how long time it will take to develop each work item. The result is documented using a table structure containing a list of prioritized and estimated requirements for the system. This constitutes the notation of a Product backlog. 
An ISDM's content, i.e. the activities, notations, and concepts, are the result of the method designer's decisions concerning the method. Therefore, they exist as a result of what the method designer has regarded as important. For example, Jayaratna et al. [35] have argued that "if $[\ldots]$ the rationale for the action is implicit then by definition the activity set cannot be considered a methodology". So, these reasons are an important part of an ISDM and they are according to Goldkuhl [23] expressed as part of an ISDM's perspective. Similar ideas are also found in Brinkkemper [8]. Hence, all of them acknowledged method rationale as an important part of an ISDM. Rossi et al. [43] have defined method rationale with the meaning of all choices made when designing the ISDM and the reasons for these choices; Ågerfalk and Wistrand [58] have made a less inclusive operationalization, with the meaning of explicating goals and values behind the ISDM. In this paper, we use the latter, less inclusive, notion of method rationale.

Consequently, it is important that the systems developers are aware of the goals and values of the adopted ISDM. Otherwise they run the risk of using the ISDM's activities, notations, and concepts based on wrong assumptions and/or with wrong interpretations [13] or "in blind and slavish adherence" [21]; this might result in not reaching the ISDM's goals and possibly a cargo cult to occur. If we return to the Daily Scrum example, the goal is to create a shared understanding of the project status, create short term planning and achieve better interaction within the ISD team. If the team does not understand this, they might not understand the basic concepts and how to carry out the activities. They might thus end up having a meeting where they have focused on the wrong things. The right questions, as suggested by the activities, have not been asked and the wrong (or no) shared understanding is the result. The reason for this is that the ISD team has missed the fundamental goals and values of this type of interaction and, as consequence, they are not adhering to the method's rationale. They think they are agile, but in reality, they are just having a coffee break standing up.

In the example of the product backlog, the goal is to have a living overview of the requirements of the system, in line with the vision. The ISD team could miss out on the goal of creating a product backlog if they do not focus on describing the work items in a distinct way, do not prioritize them, or make wrongful (or no) estimation of the work items. The value of a product backlog is to generate a higher degree of customer collaboration and to focus on working software. If the ISD team does not succeed in generating this type of product backlog, they risk ending up with a non-functional product backlog and they could be focusing on the wrong work items. In the end it could mean working on items that provide limited or no value to the customer.

\section{Conceptual Development of ISDM Cargo Cults}

As described above, an ISD team might end up in a cargo cult if they perform the wrong activities or perform activities for the wrong reasons. In the context of agile ISDM, this is often referred to as "doing agile, instead of being agile" [57]. Activities during ISD can be understood as social actions being carried out together with others in the ambition to produce an information system. Cargo cult behavior can thus be related to faulty social actions. One way to understand the concept of social action is through Kalberg's [36] analysis of Weber [54]. This analysis explains the anthropological characteristics that govern the intentions of human behavior and presents a four-fold typology of social action. The typology can be summarized as follows:

Traditional action is defined as behavior governed by habits. A social action that has a traditional foundation does no longer take rational reasons into consideration. The actor, i.e. in our case a systems developer, simply does things in the same manner as he or she has always done and does not think about whether it can be done differently. The reason for carrying a traditional action has faded into the background as this action has over a long time proven to be successful. As a result this type of action is no longer carried out for any rational reasons, only because it is usually done. 
Affectual action is based on the actors' current emotions. This type of social action is founded purely in feelings and emotive responses to internal and external stimuli. A systems developer might become inspired and emotionally embrace ideals without really having fully understood them. Actions taken as a result from this type of stimuli are not due to any rational reasoning, only emotions.

According to Weber [54], these two types of social action do not represent true rationality. However, he rather found them to be non-rational rather than irrational. The difference between irrational and non-rational social actions is that irrational social actions are founded in some type of reasoning when the actor's judgment is based on misconceptions of an ISDM, whilst the non-rational actions are not founded in any type of reasoning.

Value-based actions are founded in a set of values of some sort. This set of values takes the past, the present and the potential future into consideration. The rationality in a certain action lies in the ambition to strive towards and fulfill certain intrinsic motives. As a result of focusing on the intrinsic motives, a systems developer carrying out a value-based action does not care about the consequences of this action. The most important thing is to adhere to the intrinsic values.

Means-end actions can be understood as the focusing of a social action towards specific goals. According to Habermas [27] and Schluchter [46], the means-end rational action involves rational consideration of alternative practical means to an end, relations of the end to secondary consequences and the relative importance of different ends. This means that a systems developer chooses a certain activity to reach a calculated end.

In order to understand what faulty use of an ISDM really is, we define the misuse as being either irrational or non-rational malpractices. According to the typology presented above, irrational behavior are situations where a systems developer has failed in his/her reasoning in relation to the intended value-based or means-end rational actions. Non-rational actions do not have any foundation in reasoning at all, and thus, can only be found in traditional and affectual social actions.

\subsection{Cargo Cults in Agile ISD}

In the previous section we described faulty ISDM use as malpractices, which can be either irrational or non-rational. To understand how these malpractices can manifest themselves in an ISD organization, we must describe how they can be recognized in an empirical setting. One example of a malpractice in an agile context could be a situation related to the Daily Scrum practice we discussed earlier. Let us assume that actors in an ISD organization decide to implement this part of an agile ISDM, with the intention that this would lead to specific results. If the Daily Scrum meeting does not lead to the expected results in terms of an enhanced feeling of commitment, empowerment, and transparency, something must be wrong. A cargo cult explanation to the lack of expected results is uncontested imitation of a "Daily Scrum" behavior without understanding the method rationale, e.g. the goals and values that motivate this practice and its activities in the first place. This irrationality is the result of deficient reasoning and can lead to uncontested imitation and replication of other successful ISD organizations' use of this particular part of the ISDM. It can also lead to actual malpractice where the ISD organization does not understand why and how they should perform the task suggested by the ISDM.

Two types of irrational behavior can be identified; first, as described in the example above, we have ISD organizations that fail to properly understand the means-end rationality according to Kalberg [36]. For example, they do not understand that only reporting the status of their assigned task during a "Daily Scrum" will not lead to ISD team members' feeling empowered. In order for the team members to feel empowered a Daily Scrum needs to provide them with the possibility to make decisions. A second type of irrational behavior is the result from ignoring the actual activities and concepts that constitute the chosen agile ISDM. It could be a situation where an ISD organization embraces the values behind an agile ISDM, but lack the understanding of how to transform these values into the desired outcomes. They like the ideas, but do not have the know-how to apply them. An example of this could 
be to start planning an agile adoption without really understanding what you need to change. An ISD organization might decide to re-organize staff, change nomenclature, hire agile coaches and send people into training even though this might not be what is actually needed to improve how they conduct ISD. They fool themselves that they have a sound strategy but do not comprehend the strategic requirements.

Turning to non-rational behavior, an ISD organization could act on the basis of collective emotive reasons. Being emotive or affectual, interpreting Kalberg [36], a cargo cult scenario could be to embrace the "hype" and to "jump on the bandwagon" just because others seem to do so. This decision is not founded on any rational analysis. It rather just "feels right". Usually, this does not lead to major practical changes, but rather tend to only affect the mindset of those involved.

The second non-rational behavior, traditional social action, can also lead to malpractices; keeping parts of old ways of working can manifest this. It is often hard to change behavior and the saying "old habits are hard to kill" is well known for a reason. A typical cargo cult example of a traditional social action is to unintentionally keep old organizational roles, keep structures according to function, or keep project management processes intact even though these things might be detrimental in the ambition to achieve a successful agile ISDM implementation [49].

\subsection{A Definition of ISDM Cargo Cult}

Proper understanding of the ISDM's goals and values is fundamental for the ISDM to work efficiently. As shown earlier, an ISDM is based on values and principles, and these are important to understand in order to succeed with the method adoption. The ISDMs themselves have several practices available in order to support the implementation of the values. From a social action perspective, an ISD team could temporally exist in an ISD cargo cult. This is an unconscious dysfunction and a result of their unsuccessful adoption process. The cargo cult phenomenon stems from misconceptions concerning the underlying goals and values of the chosen ISDM and misuse of the suggested activities, notations or concepts. The incorrect use of an ISDM thus results in malpractices, which have their underlying reasons in the ISD teams' attempts to replicate others.

A cargo cult behavior could be seen as either non-rational or irrational. Also, the cargo cult can be performed for its own sake, but, a cargo cult can just as well have a separable outcome as motivation. According to Weber [53] affectual and value-based social action are not governed by trying to achievement an ulterior motive, but rather for it's own sake. This type of social action can thus be regarded as intrinsic. Ryan and Deci have put forward the Self-Determination Theory [45] where they elaborated on this concept. They described how individuals motivate themselves and defined intrinsic motivation as “...doing an activity for its inherent satisfaction rather than for some separable outcome”. On the other side, individuals consequently find extrinsic motivation. This is a construct describing social actions that are carried out in order to attain some separable outcome.

Based on our discussion above, we propose the following definition of ISDM cargo cult:

An information systems development method cargo cult is a temporally delimited dysfunction that can have a non-rational or an irrational foundation. It leads to misconceptions and malpractices and can be both intrinsically or extrinsically motivated as an information systems development team unconsciously fails in an attempt to replicate the circumstances and success of others.

\subsection{A Framework of ISDM Cargo Cult Type Situations}

In the section above, our conceptual elaboration yielded a definition that can be used to identify different types of cargo cult situations. This definition can be used as a basis for 
developing an analytical framework to explore this phenomenon. The analytical framework is shown in Fig. 1 and it is aimed to be a diagnostic tool to identify cargo cult situations in ISD.

In the proposed definition, we can identify two distinct dimensions that are used to further clarify the nature of the ISDM cargo cult behavior. The vertical dimension addresses the possible existence of rational thought in relation to the ISDM's method rationale. Remember that cargo cult behavior, in our definition, always refers to some kind of faulty ISDM application with its origins in either a misunderstanding of the reasons behind the ISDM, or no reasoning at all. Thus, being rational in these situations does not apply. Subsequently, the vertical dimension is polarized as "Non-rational" and "Irrational". Non-rational instances of ISDM cargo cult arise because no rational considerations have been done. Irrational instances occur when an ISD organization has tried to reason according to the method's rationale but failed with the ISDM adoption.

The horizontal dimension is the motivation behind why something is done. In line with Self-determination Theory [45] we suggest "Intrinsic" and "Extrinsic" motivation as the endpoints of this dimension. This serves to explain whether something is carried out for its own sake or with a separable outcome in mind. According to Weber [53], affectual and valuebased social actions can be understood as intrinsic by nature. Conversely, extrinsic motivation aligns with both traditional and means-end social actions as they both are performed to achieve some kind of purpose. That said it should be noted that traditional social action is regarded as non-rational since the ISD team does no longer reflect on the reasons for this action. Systems developers just follow traditions because of habit, regardless the original purposes of the traditions. Based on the above, we suggest two orthogonal dimensions as a basic structure for our analytical framework in Fig. 1.

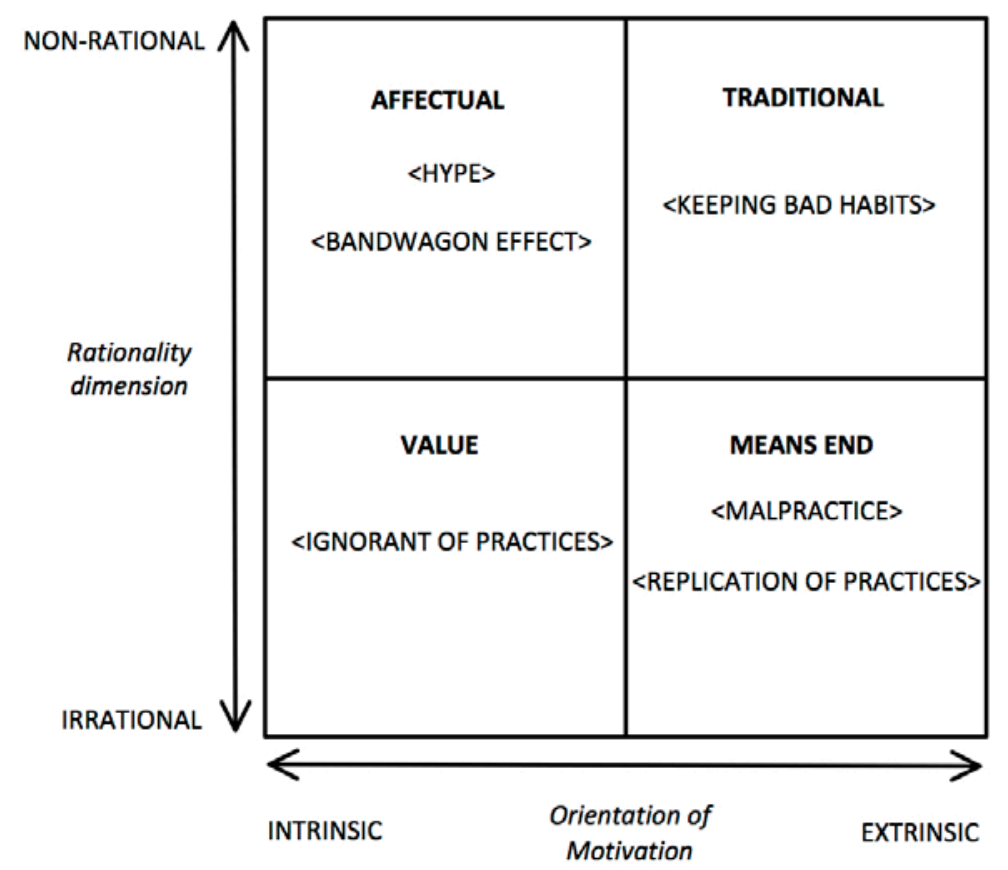

Fig. 1. A Framework of ISDM Cargo Cult Type Situations.

Following Kalberg's [36] interpretation of Weber [53], we can identify four ISDM cargo cult type situations. Continuing with our example of agile ISDMs and starting in the top left corner of our analytical framework, we have a situation where no rationality is at play. The cargo cult type situation is intrinsically motivated. We view this as an "Affectual cargo cult" situation. This describes situations where an ISD organization would "jump on the bandwagon" or simply follow the "hype" or current trend, often with a misconception of what really needs to be done and how much effort it would take. This state probably only exists for 
a short period of time as affectual behavior often is short-lived and must evolve into something else, otherwise, the idea would disappear.

In the lower left corner we find the "Value cargo cult" situation. In this situation an ISD organization embraces the true meaning behind the values of the agile ISDMs. To embrace the true meaning behind the agile values, the ISD organization would need to create a vision based on their understanding of them. They are intrinsically motivated and ignorant of how the values expressed in agile ISDMs really could shape their work. In this situation, they want to be agile, but lack the necessary know-how. The considerations they make are not founded in proper analysis of their actual potential for improvement in various ISD activities, but rather in an intrinsic desire to become agile. Their ignorance of actual adopting agile activities, concepts and notations, and which ones that could actually help them improve, lead to problems in their adoption of the agile ISDM.

The right lower corner of Fig. 1 contains the "Means-end cargo cult" situation. In this situation an ISD organization considers how to reach identified agile ISDM goals, such as faster deliveries, less documentation, and better communication with customers. In their adoption process they might try to understand how a proper operationalization of these goals could change how they act and start performing tasks extrinsically aligned with the agile ISDM. The cargo cult type situation, in this case, would be irrational with regards to Weber's [53] means-end rational social action. The irrationality stems from either malpractices, e.g. wrongful interpretations of how something is supposed to be done, or imitation and replication of practices, e.g. mimicking the behavior of other successful ISD organizations with the intent to achieve the same outcomes. The ISD organization might believe they are true to the agile goals, values and practices, but in reality, they make misconceptions and turn them into malpractices.

The last cargo cult type situation, "Traditional cargo cult", is found in the upper right corner of our analytical framework. It represents an instance where an ISD organization has adopted several agile practices in their ISD process, however not everything they are doing is agile. Some old habits have unintentionally been kept and have not been replaced by new parts from the chosen agile ISDM. As these kept method parts are based on tradition, no one in the organization is questioning them, as they have proved useful before. The idea of adopting an ISDM comes from the idea of improving what needs to be improved [4]. The reasons for using activities, concepts and notations, in various ISDMs that have previously not been understood as problematic, can be forgotten, just because they "worked fine” earlier. One of these traditional practices - or parts of them - might actually impede efficient agile ISD and result in a cargo cult behavior.

\section{Conclusion}

The aim of this conceptual paper is twofold: a) to define the concept of information systems development method cargo cult, and b) to suggest an analytical framework that could be used to identify information systems development method cargo cult situations in an information systems development organization. To this end we employed the original definition of cargo cult by Worsley [56], Weber's [54] typology for social action as interpreted by Kalberg [36], and Self-Determination Theory [45].

The proposed definition of information systems development method (ISDM) cargo cults was used for developing an analytical framework describing four different cargo cult type situations, found in Fig. 1. The framework addresses how a cargo cult can be understood as the result of irrational or non-rational considerations and whether a certain action is being carried out for intrinsic or extrinsic reasons. The analytical framework transcends the original cliché-type metaphor of cargo cults, as used in the consultancy industry, and provides possibilities for further theoretical and empirical studies to identify and as a next step understand and explain ISDM cargo cults in information systems development (ISD).

The proposed definition and our analytical framework define and conclude that by adopting an ISDM, an ISD team could risk ending up in a cargo cult situation, which we view as a temporal dysfunction resulting in misconceptions or malpractices. This occurs if the ISD 
team is intrinsically or extrinsically motivated and has a non-rational or an irrational behavior; the team will, by consequence, most likely not meet the intended goals and values that the ISDM aims to fulfill.

Previous research has addressed ISDM claimed use and adoption, and some of these studies have addressed difficulties is such adoptions. However, they have not addressed these difficulties from a cargo cult perspective. For example, deviations from the original ISDMs have been categorized as different Anti-patterns [18]. Still, Gregory et al. [24] identified a need for more research on failure in agile adoption. We provide a response to this call and an alternative view to problematize flawed ISDM adoptions. The analytical framework presented in this paper, is a tool for researchers to study pitfalls in ISDM adoption. The concept of ISDM cargo cults contributes with group-focus to ISDM-analysis, as cults can only exist on a group level. This can be compared with analysis using method-in-action [22] that seems to focus on the individual developers' use of ISDMs. We contribute to research on method rationale [58] by focusing on irrational and non-rational use of ISDMs, an aspect that have been addressed to a limited extent. Previous studies [e.g. 38, 39] have focused on a rational use of ISDMs, with the purpose of achieving rationality resonance. At the same time, cargo cult analysis can assist in explaining observations in existing research [13] about blind adherence to ISDMs or parts of them.

This paper is, to the best of our knowledge, the first attempt to frame the original socio anthropological concept of cargo cults in the field of ISD. The obvious limitation of the analytical framework is the lack of empirical validation. Henceforth, the framework and its underlying definition need to be studied further, both conceptually and empirically, in order to turn them into useful tools for researchers and practitioners. Having said that, it opens avenues for future research. As the next step, we suggest empirical studies to validate the ISDM cargo cult definition and evaluating the analytical framework, as a whole or in parts, when trying to identify, understand and explain flawed ISDM adoptions as cargo cults. As a second step, if the analytical framework is found useful, future empirical work can include finding possible solutions on how to overcome different cargo cult situations.

\section{References}

1. Avison, D. and G. Fitzgerald, Information Systems Development: Methodologies, Techniques and Tools. 1995, London, England: The McGraw-Hill Companies.

2. Avison, D. and J. Pries-Heje, Designing an appropriate information systems development methodology for different situations, in International Conference on Enterprise Information Systems, J. Filipe, J. Cordeiro, and J. Cardoso, Editors. 2007, Springer, Berlin, Heidelberg: Funchal, Madeira, Portugal.

3. Avison, D., et al., Applying methodologies for information systems development. Journal of Information Technology, 1992. 7: p. 127-140.

4. Avison, D.E. and G. Fitzgerald, Where now for development methodologies? Association for Computing Machinery. Communications of the ACM, 2003. 46(1): p. 78.

5. Beck, K., Extreme Programming explained: embrace change. 2000, Reading, MA: Addison-Wesley. 190.

6. Beck, K., et al. The agile manifesto. 2001 [cited 20123 March]; Available from: www.agilemanifesto.org.

7. Boehm, B.W., A spiral model of software development and enhancement. IEEE Computer, 1988. 21(5): p. 61-72.

8. Brinkkemper, S., Method engineering: engineering of information systems development methods and tools. Information and Software Technology, 1996. 38: p. 275-280.

9. Brooks, F.P., The Mythical Man-Month. Anniversary ed. ed. 1995, Reading: Addison-Wesley.

10. Brown, W.J., et al., AntiPatterns: Refactoring Software, Architectures, and Projects in Crisis. 1998, New York, NY, USA: Wiley and Sons. 
11. Cerf, V.G., Cargo Cults and Information Technology Development. IEEE Internet Computing, 2013. 14(4): p. 96-96.

12. Cockburn, A., Writing Effective Use Cases. The Crystal Collection fo Software Professionals. 2000, Boston: Addison-Wesley Professional.

13. Conboy, K., Agility from First Principles: Reconstructing the Concept of Agility in Information Systems Development. Information Systems Research, 2009. 20(3): p. 329-354.

14. Consortium, D., Dynamic Systems Develoment Method , v. 3, 1997, DSDM Consortium: Ashford, England.

15. Daemons, M., Cargo Cult Agile, 2007.

16. Dalton, D., Cargo Cults and Discursive Madness. Oceania, 2000. 70(1).

17. El-Haik, B.S., A Software Design for Six Sigma: A Roadmap for Excellence. 2010.

18. Eloranta, V.-P., K. Koskimies, and T. Mikkonen, Exploring ScrumBut - An empirical study of Scrum anti-patterns. Information and Software Technology, 2015. 74: p. 194-203.

19. Fernaeus, Y., et al. Are We Living in a Robot Cargo Cult? in HRI '09 Proceedisng of the 4th ACM/IEEE International conference on Human robot interaction. 2009. La Jolla, CA, USA: ACM.

20. Feynman, R. Cargo Cult Science. 1974; Available from: http://calteches.library.caltech.edu/51/2/CargoCult.htm.

21. Fitzgerald, B., Formalised systems development methodologies: A critical perspective. Information Systems Journal, 1996. 6(1): p. 3-23.

22. Fitzgerald, B., N.L. Russo, and E. Stolterman, Information Systems Development Methods in Action. 2002, Berkshire, UK: McGraw-Hill.

23. Goldkuhl, G., M. Lind, and U. Seigerroth, Method integration: The need for a learning perspective. IEE Proceedings - Software, 1998. 145(4): p. 113-118.

24. Gregory, P., et al., The challenges that challenge: Engaging with agile practitioners' concerns. Information and Software Technology, 2016. 77: p. 92-104.

25. Grünschloss, A., Waiting for the "Big Beam": UFO Religions and "Ufological" Themes in New Religious Movements, in The Oxford Handbook of New Religious Movements, J.R. Lewis, Editor. 2009, Oxford University Press: Oxford, England.

26. Guiart, J., John Frum Movement in Tanna. Oceania, 1952. 22(3): p. 165-177.

27. Habermas, J., The theory of communicative action1. Reason and the rationalization of society. 1984, Cambridge: Polity Press. 2 vol.

28. Heikkila, V.T., M. Paasivaara, and C. Lassenius, ScrumBut, but does it matter? A mixed-method study of the planning process of a multi-team scrum organization, in 2013 ACM / IEEE International Symposium on Empirical Software Engineering and Measurement, ESEM 20132013: Baltimore, MD, USA. p. 85-94.

29. Holmquist, L.E., Prototyping: generating ideas or cargo cult designs? Interactions Robots, 2005. 12(2): p. 48-54.

30. Iivari, J. and J. Maansaari, The Usage of Systems Development Methods: are we stuck to old practice? Information and Software Technology, 1998. 40: p. 501-510.

31. Iivari, J., H. Rudy, and H.K. Klein, A dynamic framework for classifying information systems development methodologies and approaches. Journal of Management Information Systems, 2001. 17(3): p. 179-218.

32. Introna, L.D. and E.A. Whitley, Against Method-ism: Exploring the limits of method. Information Technology \& People, 1997. 10(1): p. 31-45.

33. Jarvie, I.C., Theories of Cargo Cults: A Critical Analysis. Oceania, 1963. 34(1): p. 131.

34. Jayaratna, N., Understanding and evaluating methodologies. 1994, London: McGrawHill.

35. Jayaratna, N., P. Holt, and T. Wood-Harper, Criteria for Methodology Choice in Information System Development. The Journal of Contemporary Issues in Business and Government, 1999. 5(2): p. 30-34. 
36. Kalberg, S., Max Weber's Types of Rationality: Cornerstones for the Analysis of Rationalization Processes in History. American Journal of Sociology, 1980. 85(5): p. 1145-1179.

37. Karlsson, F. and K. Hedström. Negotiating a Systems Development Method. in The 17th International Conference on Information Systems Development (ISD2008). 2008. Paphos, Cyprus.

38. Karlsson, F. and P.J. Ågerfalk, Method Configuration: Adapting to Situational Characteristics while Creating Reusable Assets. Information and Software Technology, 2004. 46(9): p. 619-633.

39. Karlsson, F. and P.J. Ågerfalk, Exploring Agile Values in Method Configuration. European Journal of Information Systems, 2009. 18(4): p. 300-316.

40. McConnell, S., Cargo Cult Software Engineering. IEEE Software, 2000. March/April: p. 11-13.

41. Oinas-Kukkonen, H., Method rationale in method engineering and use, in Proceedings of the IFIP TC8, WG8.1/8.2 working conference on method engineering on Method engineering, , et al., Editors. 1996, Chapman \& Hall: Atlanta, USA. p. 8793.

42. Päivärinta, T., M.K. Sein, and T. Peltola, From ideals towards practice: paradigmatic mismatches and drifts in method deployment. Information Systems Journal, 2010. 20(5): p. 481-516.

43. Rossi, M., et al., Managing Evolutionary Method Engineering by Method Rationale. Journal of Association of Information Systems, 2004. 5(9): p. 356-391.

44. Russo, N.L. and E. Stolterman, Exploring the assumptions underlying information systems methodologies: their impact on past, present and future ISM research. Information Technology \& People, 2000. 13(4): p. 313-327.

45. Ryan, R.M. and E.L. Deci, Instrinsic and Extrinsic Motivations: Classic Definitions and New Directions. Contemporary Educational Psychology, 2000. 25: p. 54-67.

46. Schluchter, W., The Rise of Western Rationalism : Max Weber's Developmental History. 1981, Berkely: University of California Press,.

47. Schwaber, K. and M. Beedle, Agile Software Development with Scrum. 2001, Upper Saddle River, NJ: Prentice Hall.

48. Shore, J., Cargo Cult Agile, 2008.

49. Soria, J.L., Cargo cult agile, 2012.

50. Standish Group, CHAOS report 2000, 2000.

51. Standish Group, CHAOS report 2008, 2008.

52. Standish Group, Chaos report 2012, 2012.

53. Weber, M., The theory of social and economic organization. 1947, New York: The free press. 436.

54. Weber, M., Economy and society. 1978, Berkeley, CA: University of California Press.

55. Williams, F.E., The Vailala Madness and the Destruction of Native Ceremonies in the Gulf Division, in The Vailala Madness' and Other Essays, E. Schwimmer, Editor. 1979, The University Press of Hawaii: Honolulu, HI.

56. Worsley, P., The Trumpet Shall Sound - A Study of 'Cargo' Cults in Melanesia. 1957, London: Macgibbon \& Kee.

57. Zieris, F. and S. Salinger, Doing Scrum Rather Than Being Agile: A case Study on Actual Nearshoring Practices, in IEEE 8th International Conference on Global Software Engineering (ICGSE)2013, IEEE: Bari, Italy.

58. Ågerfalk, P.J. and K. Wistrand, Systems Development Method Rationale: A Conceptual Framework for Analysis, in Proceedings of the 5th International Conference on Enterprise Information Systems (ICEIS 2003), O. Camp, et al., Editors. 2003, Escola Superior de Tecnologia do Instituto Politécnico de Setúbal: Setúbal, Portugal. p. 185-190. 